\title{
Poor quality of life and functioning in bipolar disorder
}

\author{
Louisa G. Sylvia ${ }^{1,2^{*}}$, Rebecca E. Montana ${ }^{1}$, Thilo Deckersbach ${ }^{1,2}$, Michael E. Thase ${ }^{3}$, Maurcio Tohen ${ }^{4}$, \\ Noreen Reilly-Harrington ${ }^{1,2}$, Melvin G. McInnis ${ }^{5}$, James H. Kocsis ${ }^{6}$, Charles Bowden ${ }^{7}$, Joseph Calabrese ${ }^{8}$, \\ Keming Gao ${ }^{8}$, Terence Ketter ${ }^{9}$, Richard C. Shelton ${ }^{10}$, Susan L. McElroy ${ }^{11,12}$, Edward S. Friedman ${ }^{13}$, \\ Dustin J. Rabideau ${ }^{14}$ and Andrew A. Nierenberg ${ }^{1,2}$
}

\begin{abstract}
Background: This study explores the association of demographic and clinical features with quality of life and functioning in individuals with bipolar disorder.

Methods: Adult participants ( $N=482$ ) with bipolar I or II disorder were enrolled in a comparative effectiveness study across eleven study sites and completed baseline measures of medical and psychiatric history, current mood, quality of life, and functioning. Participants with at least mildly depressive or manic/hypomanic symptomatic severity were randomized to receive lithium or quetiapine in addition to adjunctive personalized treatment for 6 months.

Results: Participants with more severe depressive and irritability symptoms had lower quality of life and higher functional impairment. All psychiatric comorbid conditions except substance use disorder were associated with worse quality of life. On average, females had lower quality of life than males. Patients who were married, living as married, divorced, or separated had worse functional impairment compared with patients who were single or never married. A composite score of social disadvantage was associated with worse functioning and marginally associated with worse quality of life. Symptom severity did not moderate the effect of social disadvantage on quality of life or functioning.
\end{abstract}

Conclusions: Our findings highlight that depression, irritability, and psychiatric comorbid conditions negatively impact quality of life and functioning in bipolar disorder. The study suggests that individuals with social disadvantage are at risk for functional impairment.

Trial Registration This study is registered with ClinicalTrials.gov. Identification number: NCT01331304

Keywords: Bipolar disorder, Quality of life, Functioning, Social disadvantage

\section{Background}

Individuals with bipolar disorder frequently experience lower quality of life and worse functioning than the general population (Abraham et al. 2014; Sierra et al. 2005; Sylvia et al. 2013), even when not in a mood episode (Fulford et al. 2014; Gazalle et al. 2007; Shabani et al. 2013). Moreover, those who experience a lower quality of life exhibit higher inter-episode impulsivity and more cognitive impairment as well as residual depressive and psychotic symptoms (Depp et al. 2006; Victor et al. 2011).

\footnotetext{
*Correspondence: Isylvia2@partners.org

${ }^{1}$ Department of Psychiatry, Massachusetts General Hospital, 50 Staniford Street, Suite 580, Boston, MA 02114, USA

Full list of author information is available at the end of the article
}

Beyond psychiatric symptoms, other sources of stress could contribute to lower quality of life and functioning. One complex construct that might explain these deficits is social disadvantage. Social disadvantage is a composite measure composed of education level, employment status, income level, and occupational prestige (Duncan 1961). Bipolar disorder is associated with higher rates of unemployment and disability (Fulford et al. 2014; Sanchez-Moreno et al. 2009; Sylvia et al. 2013), and greater social disadvantage has been associated with higher levels of stress, higher mortality, and decreased access to healthcare (Adler and Newman 2002; Brennan et al. 2013; Mielck et al. 2014). Thus, it remains unclear as regards the association of social 
disadvantage with quality of life and functioning in bipolar disorder.

The purpose of this paper is to explore the determinants of quality of life and functioning, especially the construct of social disadvantage, in a representative cohort of bipolar patients who participated in a comparative effectiveness trial.

\section{Methods}

\section{Participants}

We enrolled 482 participants across eleven study sites for a comparative effectiveness trial [Bipolar CHOICE study-(Nierenberg et al. 2014)] that compared lithium with quetiapine in addition to adjunctive personalized treatment. The main inclusion criteria were being at least 18 years of age; having a primary diagnosis of bipolar I or II disorder; and being at least mildly symptomatic, either depressed, or manic/hypomanic. Participants were excluded if they were currently a psychiatric or medical inpatient, or had a history of failed treatment response to lithium or quetiapine, current lithium or quetiapine usage, and any contraindication to either medication (e.g., severe cardiovascular disease, renal disease, or pregnancy).

\section{Study design}

The clinical and health outcomes initiative in comparative effectiveness for bipolar disorder study (Bipolar CHOICE) was a 6-month, parallel group, randomized controlled trial that compared the effectiveness of a second generation antipsychotic (quetiapine) and a classic mood stabilizer (lithium) (Nierenberg et al. 2014). Each group received adjunctive personalized treatments (APTs), or any other medications as needed, except the quetiapine group $(\mathrm{QTP}+\mathrm{APT})$ could not be prescribed lithium $(\mathrm{Li}+\mathrm{APT})$ or other antipsychotics and the lithium group could not be prescribed antipsychotics. APTs allow for greater generalizability and flexibility, as opposed to the strict monotherapy that patients typically receive in standard comparative effectiveness trials. APT was both evidence based and personalized to current symptoms, prior treatment history, and course of illness (Suppes et al. 2005).

Patients completed baseline measures assessing medical and psychiatric history as well as current mood, quality of life, and functioning and were then randomized to either $\mathrm{Li}+\mathrm{APT}$ or QTP + APT. This report focuses on the baseline measures related to the quality of life.

\section{Measures \\ The mini international neuropsychiatric interview (Sheehan et al. 1997) (MINI 6.0)}

The mini international neuropsychiatric interview is a clinician-administered, semistructured diagnostic interview that was designed specifically for clinical trials and epidemiological studies (Sheehan et al. 1997). The MINI was administered at the baseline visit to determine diagnoses, which correspond to DSM-IV-TR or ICD-10 diagnoses.

\section{Quality of life, enjoyment, and satisfaction questionnaire (Endicott et al. 1993) (Q-LES-Q)}

The Q-LES-Q is a self-report measure that assesses subjective quality of life (i.e., physical health, subjective feelings, leisure activities, and social relationships) over the previous week. Participants rate items on a scale from a 5-point scale that ranges from "very poor" to "very good."

\section{Longitudinal interval follow-up evaluation-range of impaired functioning tool (Leon et al. 2000) (LIFE-RIFT)}

The LIFE-RIFT assesses the extent to which psychopathology has impacted current functioning in work, household chores, interpersonal relationships with partner, family, and friends, recreational activities, and life satisfaction. A reliable and valid measure of functioning, the LIFE-RIFT, assesses impairment in four areas-work (employment, household, school), interpersonal relationships (spouse, child, other relatives, friends), satisfaction, and recreation.

\section{Social disadvantage}

Social disadvantage was defined as the sum of three dichotomous variables: household income ( 1 if less than $\$ 25,000,0$ if $\$ 25,000$ or more), education status (1 if highest level was high school or less, 0 if at least some college), and employment status (1 if unemployed/ disabled, 0 if employed/student/retired). We omitted occupational prestige in the study's definition of social disadvantage as it was not assessed given the subjectivity of this component and that prestige likely varies for this clinical population (i.e., based on high rates of disability, any job could, and probably should, be prestigious for an individual with bipolar disorder) (Oakes and Rossi 2003). It has been widely noted that low socioeconomic status is correlated with psychiatric illness and higher rates of disability (Hirschfeld et al. 2003; Lorant et al. 2003).

\section{Bipolar inventory of symptoms scale (Bowden et al. 2007)}

The BISS is a clinician-administered, structured interview that was originally developed with a focus on assessing bipolar symptoms in an outpatient sample. Items are assessed on a 5-point Likert scale, 0 indicating not at all to 4 indicating severe. The BISS measures the domains of mania, depression, irritability, anxiety, and psychosis (Thompson et al. 2010). BISS domain scores were re-scaled to range from 0 to 40 .

\section{Statistical analysis}

Descriptive data at baseline were reported as frequencies or mean with standard deviation. Linear regression 
models were fit to explore whether baseline quality of life (Q-LES-Q) and functioning (LIFE-RIFT) were associated with baseline demographics, clinical severity, social disadvantage, and current psychiatric comorbid conditions. The composite score of social disadvantage (calculated based on household income, education level, and employment status) ranged from 0 to 3 , corresponding, respectively, to no, mild, moderate, and severe disadvantage. Variables (excluding comorbid conditions) were considered for inclusion in the multivariate linear regression model if univariate screening $p$ value was less than 0.25 and were ultimately included in the model if the adjusted $p$ value was less than 0.05 .

To explore whether clinical symptom severity (BISS total) moderated the effect of social disadvantage on quality of life and functioning, we fit linear regression models with main effects for disadvantage and clinical severity as well as their interaction. If the interaction was significant, we determined there to be evidence of moderation. For these moderator analyses, we conducted a sensitivity analysis separating social disadvantage into each of its three components (rather than using the categorical composite score) to determine whether our conclusions were sensitive to this composite definition. Statistical analyses were performed using SAS 9.4 (Cary, NC, USA) and R version 3.2.1 (www.r-project.org).

\section{Results}

At baseline, the mean quality of life (Q-LES-Q) score was $44.3(\mathrm{SD}=17.8)$, and the mean functioning (LIFE-RIFT) score was $14.2(\mathrm{SD}=3.4)$. The baseline associations of quality of life and functioning with demographics, clinical severity, current psychiatric comorbid conditions, and social disadvantage are reported in Table 1. On average, females had lower quality of life than males. Patients who were married, living as married, divorced, or separated had worse functional impairment (higher scores on LIFERIFT) compared with patients who were single or never married. Age, ethnicity, and race were not significantly related to quality of life or functioning.

Participants with greater clinical symptom severity measured with BISS (total, depression, anxiety, irritability, and psychosis) had lower quality of life and higher functional impairment (Table 1). Patients with greater manic severity reported marginally better quality of life. No association was found between severity of manic symptoms and functioning. Only BISS depression and BISS irritability remained significant in both multivariate models (Q-LES-Q and LIFE-RIFT). We also found that although most of the BISS symptom domains (anxiety, irritability, depression, and psychosis) were associated with social disadvantage, mania was not (Table 2). In Fig. 1, we display the marginal (unadjusted) and conditional (adjusted for other covariate in model) effects of depressive and irritability symptom severity on quality of life and functioning. In both cases, the marginal and conditional effects of BISS depression were similar, while the effect of BISS irritability decreased when adjusting for BISS depression.

Social disadvantage was significantly associated with worse functioning and marginally associated with worse quality of life $(p=0.07)$ (Table 1$)$. Each component (income, education, and employment) was at least marginally associated with functioning, such that patients with lower income, lower education, and unemployed/ disabled had worse functioning (all $p<0.07$ ). Those who were unemployed or disabled were marginally associated with lower quality of life $(p=0.06)$, whereas neither income nor education was significantly associated with quality of life.

All psychiatric comorbid conditions, except substanceuse disorder, were significantly associated with worse quality of life (Table 1). Panic disorder, agoraphobia, social disorder, ADHD, and any anxiety disorder were also associated with worse functional impairment. The total number of psychiatric comorbid conditions was associated with quality of life and functioning, such that for each additional comorbid condition, the mean quality of life decreased by 3.8 points and the mean functional impairment increased by 0.7 points (both $p<0.001$ ). We found no evidence to suggest that clinical symptom severity moderated the effect of social disadvantage on quality of life and functioning (both $p>0.05$ ).

\section{Discussion}

Our results are consistent with earlier reports that show that individuals with bipolar disorder often experience overall poor quality of life and life functioning (Abraham et al. 2014; Sierra et al. 2005; Sylvia et al. 2013). We also found that females had lower quality of life than males. Patients who were married, living as married, divorced, or separated had worse functional impairment compared with patients who were single or never married. All psychiatric comorbid conditions, except substance-use disorder, were associated with worse quality of life. Panic disorder, agoraphobia, social disorder, ADHD, and any anxiety disorder were also associated with worse functional impairment. These findings are consistent with previous studies examining comorbid conditions and functioning in bipolar disorder (Mendlowicz and Stein 2000; Otto et al. 2006; Rapaport et al. 2005; Simon et al. 2004).

Social disadvantage was significantly associated with worse functioning and symptoms, but unexpectedly only marginally associated with quality of life. The multivariate models suggested that depression and irritability together were the strongest indicators of poor quality of life and 
Table 1 Baseline correlations of quality of life and functioning with demographics, clinical severity, social disadvantage, and current psychiatric comorbidities

\begin{tabular}{|c|c|c|c|c|c|}
\hline \multirow[t]{2}{*}{ Variable } & \multirow[t]{2}{*}{$\%(n)$ or mean + SD } & \multicolumn{2}{|l|}{ Q-LES-Q } & \multicolumn{2}{|l|}{ LIFE-RIFT } \\
\hline & & Coefficient & $p$ value & Coefficient & $p$ value \\
\hline \multicolumn{6}{|l|}{ Demographics } \\
\hline Age & $38.9+12.1$ & 0.03 & 0.65 & 0.01 & 0.34 \\
\hline Female (REF: male) & $59 \%(283)$ & -4.6 & 0.006 & 0.5 & 0.10 \\
\hline Hispanic/Latino (REF: not) & $11 \%(53)$ & 2.1 & 0.43 & 0.6 & 0.21 \\
\hline Race & & & 0.94 & & 0.83 \\
\hline White & $72 \%(348)$ & REF & & REF & \\
\hline Black & $20 \%(96)$ & -1.1 & & 0.2 & \\
\hline Asian & $3 \%(16)$ & 0.7 & & 0.1 & \\
\hline Native American & $<1 \%(1)$ & 5.6 & & 0.9 & \\
\hline Other & $4 \%(21)$ & 2.2 & & 0.9 & \\
\hline Marital status & & & 0.66 & & 0.05 \\
\hline Single/never married & $47 \%(225)$ & REF & & REF & \\
\hline Married/living as married & $31 \%(150)$ & -2.1 & & 0.9 & \\
\hline Divorced/separated & $21 \%(100)$ & -1.3 & & 0.8 & \\
\hline Widowed & $1 \%(7)$ & 2.3 & & 0.2 & \\
\hline \multicolumn{6}{|l|}{ Clinical symptom severity } \\
\hline BISS total & $56.1+18.8$ & -0.46 & $<0.001$ & 0.09 & $<0.001$ \\
\hline BISS depression & $17.5+7.3$ & -1.64 & $<0.001$ & 0.29 & $<0.001$ \\
\hline BISS mania & $9.2+6.4$ & 0.23 & 0.08 & -0.03 & 0.29 \\
\hline BISS anxiety & $15.9+8.5$ & -0.92 & $<0.001$ & 0.17 & $<0.001$ \\
\hline BISS irritability & $16.8+8.5$ & -0.65 & $<0.001$ & 0.15 & $<0.001$ \\
\hline BISS psychosis & $2.8+4.5$ & -0.48 & 0.007 & 0.15 & $<0.001$ \\
\hline \multicolumn{6}{|l|}{ Social disadvantage } \\
\hline Household income $<\$ 25 \mathrm{~K}$ (REF: $\geq 25 \mathrm{~K})$ & $52 \%(249)$ & -1.7 & 0.30 & 0.6 & 0.06 \\
\hline High school diploma or less (REF: at least some college) & $25 \%(122)$ & -2.0 & 0.29 & 0.8 & 0.03 \\
\hline Unemployed/disabled (REF: employed/student/retired) & $51 \%(244)$ & -3.1 & 0.06 & 0.7 & 0.03 \\
\hline Social disadvantage & & & 0.07 & & 0.03 \\
\hline No disadvantage & $28 \%(133)$ & REF & & REF & \\
\hline Mild & $30 \%(142)$ & -1.1 & & 0.6 & \\
\hline Moderate & $29 \%(138)$ & -5.3 & & 0.8 & \\
\hline Severe & $13 \%(65)$ & -2.2 & & 1.4 & \\
\hline \multicolumn{6}{|l|}{ Current psychiatric comorbidity } \\
\hline Generalized anxiety disorder & $22 \%(107)$ & -5.9 & 0.002 & 0.6 & 0.11 \\
\hline Substance use disorder & $23 \%(109)$ & -0.6 & 0.76 & 0.2 & 0.49 \\
\hline Obsessive-compulsive disorder & $11 \%(51)$ & -4.9 & 0.02 & 0.9 & 0.08 \\
\hline Panic disorder & $23 \%(112)$ & -8.7 & $<0.001$ & 0.8 & 0.03 \\
\hline Agoraphobia & $37 \%(176)$ & -5.8 & 0.001 & 0.9 & 0.003 \\
\hline Social disorder & $25 \%(119)$ & -5.3 & 0.005 & 0.8 & 0.03 \\
\hline ADHD & $34 \%(161)$ & -4.2 & 0.02 & 1.0 & 0.002 \\
\hline Any anxiety disorder ${ }^{a}$ & $58 \%(277)$ & -8.9 & $<0.001$ & 1.2 & $<0.001$ \\
\hline
\end{tabular}

Q-LES-Q quality of life enjoyment and satisfaction questionnaire, LIFE-RIFT longitudinal interval follow-up evaluation-range of impaired functioning tool, REF reference level, BISS bipolar inventory of symptoms scale, ADHD attention deficit hyperactivity disorder. Coefficients and $p$ values based on linear regression models. Coefficients represent the change in Q-LES-Q/LIFE-RIFT per 1-point increase for continuous variables and change from reference level for categorical variables

${ }^{a}$ Includes patients with any of the following current diagnoses (based on MINI): panic disorder, agoraphobia, social phobia, and generalized anxiety disorder

functioning in individuals with bipolar disorder. Consistent with prior studies (Boylan et al. 2004; McElroy et al. 2001; Simon et al. 2004), our findings suggest that current symptom severity and psychiatric comorbid conditions negatively impact quality of life and functioning in bipolar disorder. 
Table 2 Association between BISS symptom domains and social disadvantage

\begin{tabular}{|c|c|c|c|c|c|}
\hline & \multicolumn{4}{|c|}{ Social disadvantage score } & \multirow{2}{*}{$\begin{array}{l}\text { Overall } \\
p \text { value }\end{array}$} \\
\hline & 0-REF & 1 & 2 & 3 & \\
\hline \multicolumn{6}{|c|}{ BISS domain score } \\
\hline Depression & $16.3+7.1$ & $16.7+7.1$ & $18.6+7.7^{a}$ & $19.3+7.0^{a}$ & 0.006 \\
\hline Mania & $8.13+5.9$ & $9.2+6.8$ & $9.9+6.9$ & $9.4+4.8$ & 0.15 \\
\hline Anxiety & $13.8+8.0$ & $15.6+8.3$ & $17.0+9.0^{a}$ & $18.3+8.4^{a}$ & 0.001 \\
\hline Irritability & $15.9+8.3$ & $15.2+8.3$ & $17.7+8.9$ & $20+7.9^{a}$ & 0.0006 \\
\hline Psychosis & $1.7+3.2$ & $2.6+4.3$ & $3.5+5.4^{a}$ & $4.0+4.6^{a}$ & 0.0006 \\
\hline
\end{tabular}

REF reference level

a Pairwise comparison with 0 -REF is significant $(p<0.05)$
These results support findings in other clinical populations that social disadvantage can have a negative effect on the overall functioning of individuals with bipolar disorder (Bowie et al. 2010; Huxley and Baldessarini, 2007; Judd and Akiskal 2003). Social disadvantage has been associated with higher levels of stress, greater likelihood of depression, and higher rates of disability (Lorant et al. 2003). Given the frequency of depression and irritability as well as severity of these symptoms in this clinical population, it is perhaps not surprising that these symptoms were primarily associated with social disadvantage among individuals with bipolar disorder; however, we expected that mania would correlate with this outcome

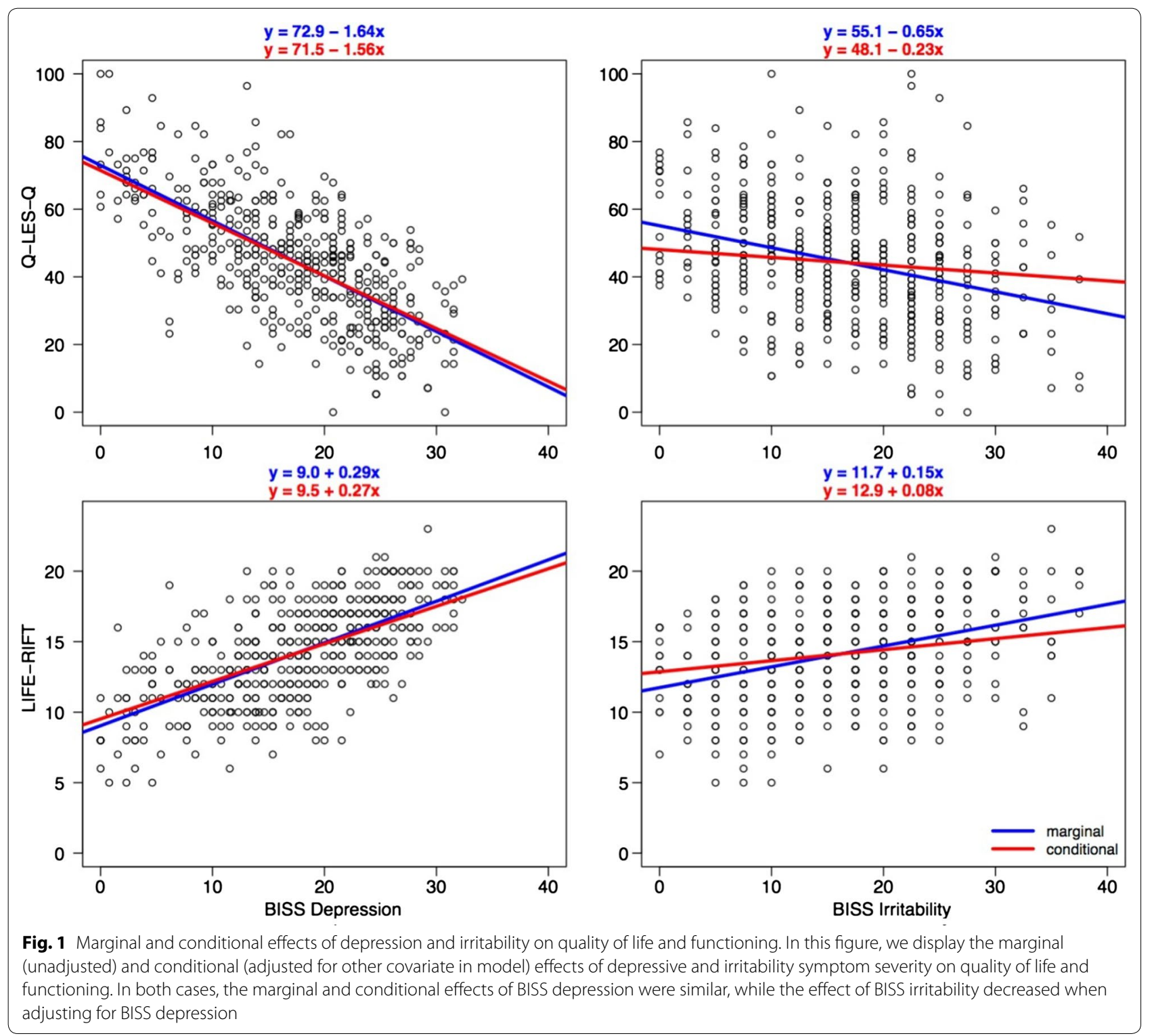


given the degree to which these symptoms can disrupt one's functioning (e.g., ability to work, obtain high incomes). It is likely that we did not find this correlation as most participants were depressed (opposed to manic) throughout the duration of the study (Tohen et al. 2015) (see Table 1).

Interestingly, while patients with greater clinical severity (i.e., total, depression, anxiety, irritability) had lower quality of life, patients with greater manic severity reported marginally better quality of life. No association was found between manic severity and functioning, consistent with the literature (Rosa et al. 2010), and mania was not associated with social disadvantage. These findings could be explained by the use of a self-report measure of quality of life as this relies on the insight and perception of the individual, which are often altered during this mood state with grandiosity and expansiveness. This study is unique in its analysis of the association of mood symptoms with social disadvantage in a large sample of bipolar I and bipolar II patients; however, it should be noted that education and employment (two components of social disadvantage) are potentially overlapping constructs of quality of life and functioning. Further, the limited inclusion and exclusion criteria may have enhanced generalizability of our findings. However, these participants were recruited for a study at academic medical centers, and thus, replication in community settings is warranted.

\section{Conclusions}

Individuals with bipolar disorder commonly report poor quality of life and have difficulty functioning. This study also sought to explore those who might be at greater risk for poor outcomes by examining the impact of a composite variable of several, overlapping demographic aspects, or social disadvantage. It appears that depression and irritability (but not mania) worsen quality of life and functioning in this clinical population. Overall, these data suggest that better interventions for individuals with social disadvantage, depression, and irritability are needed as they may be at greater risk for improvement in quality of life and functioning.

\footnotetext{
Authors' contributions

LS contributed to the study design, assisted with study coordination, oversaw the analyses, and wrote the manuscript. RM assisted in planning the data analyses and writing the manuscript. TD assisted with conducting the study, overseeing the study analyses, and writing the manuscript. MT assisted with conducting the study and writing the manuscript. NRH assisted with conducting the study and writing the manuscript. MM assisted with conducting the study and writing the manuscript. JK assisted with conducting the study and writing the manuscript. CB assisted with conducting the study and writing the manuscript. JC assisted with conducting the study and writing the manuscript. KG assisted with conducting the study and writing the manuscript. TK assisted with conducting the study and writing the manuscript. RS assisted with conducting the study and writing the manuscript. SM assisted with conducting the study and writing the manuscript. EF assisted with conducting
}

the study and writing the manuscript. DR conducted the statistical analyses and assisted in writing the manuscript. AN conceived of the study, and participated in its design and coordination and helped to draft the manuscript. All authors read and approved the final manuscript.

\section{Author details}

${ }^{1}$ Department of Psychiatry, Massachusetts General Hospital, 50 Staniford Street, Suite 580, Boston, MA 02114, USA. ${ }^{2}$ Harvard Medical School, 25 Shattuck Street, Boston, MA 02115, USA. ${ }^{3}$ Department of Psychiatry, University of Pennsylvania School of Medicine, Philadelphia, PA, USA. ${ }^{4}$ Department of Psychiatry and Behavioral Sciences, University of New Mexico, Health Sciences Center, Albuquerque, NM, USA. ${ }^{5}$ Department of Psychiatry, University of Michigan, Ann Arbor, MI, USA. ${ }^{6}$ Department of Psychiatry, Weill Cornell Medicine, New York City, NY, USA. ${ }^{7}$ Department of Psychiatry, University of Texas Health Science Center at San Antonio, San Antonio, TX, USA. ${ }^{8}$ Bipolar Disorders Research Center, University Hospital's Case Medical Center, Case Western Reserve University, Cleveland, OH, USA. ${ }^{9}$ Department of Psychiatry and Behavioral Sciences, Stanford University School of Medicine, Stanford, CA, USA. ${ }^{10}$ Department of Psychiatry, University of Alabama Birmingham School of Medicine, Birmingham, AL, USA. ${ }^{11}$ Lindner Center of HOPE, Mason, $\mathrm{OH}$, USA. ${ }^{12}$ Department of Psychiatry, University of Cincinnati College of Medicine, Cincinnati, OH, USA. ${ }^{13}$ University of Pittsburgh School of Medicine, Pittsburgh, PA, USA. ${ }^{14}$ Biostatistics Center, Massachusetts General Hospital, Boston, MA, USA.

\section{Acknowledgements}

This study was funded by the Agency of Healthcare Research and Quality (AHRQ) Grant R01 HS019371-01

\section{Competing interests}

Dr. Sylvia was a shareholder in Concordant Rater Systems and serves as a consultant for United Biosource Corporation and Clintara. She receives royalties from New Harbinger. Ms. Montana reports no competing interests. Dr. Deckersbach's research has been funded by NIH, NIMH, NARSAD, TSA, IOCDF, Tufts University, DBDAT, Otsuka Pharmaceuticals and Cogito, Inc. He has received honoraria, consultation fees and/or royalties from the MGH Psychiatry Academy, BrainCells Inc., Clintara, LLC., Systems Research and Applications Corporation, Boston University, the Catalan Agency for Health Technology Assessment and Research, the National Association of Social Workers Massachusetts, the Massachusetts Medical Society, Tufts University, NIDA, NIMH, and the Oxford University Press. He has also participated in research funded by DARPA, NIH, NIMH, NIA, AHRQ, PCORI, Janssen Pharmaceuticals, The Forest Research Institute, Shire Development Inc., Medtronic, Cyberonics, Northstar, Takeda, and Sunovion. Dr. Thase has been an advisor/ consultant: Alkermes; Allergan; AstraZeneca; Bristol-Myers Squibb Company; Cerecor, Inc.; Eli Lilly \& Co.; Fabre-Kramer Pharmaceuticals, Inc.; Forest Laboratories; Gerson Lehrman Group; GlaxoSmithKline; Guidepoint Global; H. Lundbeck A/S; MedAvante, Inc;; Merck and Co. Inc. (formerly Schering Plough and Organon); Moksha8; Naurex, Inc.; Neuronetics, Inc;; Novartis; Ortho-McNeil Pharmaceuticals (Johnson \& Johnson; Janssen); Otsuka; Pamlab, L.L.C. (Nestle); Pfizer (formerly Wyeth Ayerst Pharmaceuticals); Shire US Inc.; Sunovion Pharmaceuticals, Inc.; ; Takeda; and Trius Therapeutical, Inc. Dr. Thase receives grant funding from the Agency for Healthcare Research and Quality; Alkermes; AssureRx; Avanir; Forest Pharmaceuticals; Janssen; National Institute of Mental Health; Otsuka Pharmaceuticals. He has equity holdings in MedAvante, Inc. and receives royalty income from American Psychiatric Foundation, Inc., Guilford Publications, Herald House, the Oxford University Press, and W.W. Norton \& Company. His wife is employed as the Group Scientific Director for Peloton Advantage which does business with Pfizer. Dr. Tohen was an employee of Lilly (1997 to 2008) and has received honoraria from or consulted for Abbott, AstraZeneca, Alkermes, Bristol Myers Squibb, GlaxoSmithKline, Lilly, Johnson \& Johnson, Otsuka, Merck, Sunovion, Forest, Roche, Elan, Lundbeck, Teva, Pamlab, Minerva, Pfizer, Wyeth and Wiley Publishing; his spouse was a full time employee at Lilly (1998-2013). Dr. Reilly-Harrington receives royalties from the Oxford University Press, the American Psychological Association, and New Harbinger. She serves as a consultant for United Biosource Corporation and was a shareholder in Concordant Rater Systems. Dr. McInnis has received grants for research support from NIMH, the Heinz C Prechter Research Fund, and the Michigan Institute for Clinical Health Research (MICHR). MM has received consulting income from the Qatar National Research Foundation, Janssen, and Merck Pharmaceuticals. Dr. Kocsis has received research grants 
and contracts from AHRQ, NIMH, Pritzker Consortium, Qatar National Research Fund, and Rockefeller Treatment Development Fund. He holds an Elan. Patent (No. 8,853,279), entitled "Method for Determining Sensitivity or Resistance to Compounds That Activate the Brain Serotonin System." Dr. Bowden is conducting a biological study in mood disorders sponsored by Myriad Inc. He has no competing interests. Dr. Calabrese has received federal funding from the Department of Defense, Health Resources Services Administration and National Institute of Mental Health as well as grant support from: Abbott Laboratories; AstraZeneca; Bristol-Myers Squibb Company; Cephalon, Inc. (now Teva Pharmaceutical Industries Ltd.); Dainippon Sumitomo Pharma Co., Ltd.; GlaxoSmithKline; Janssen Pharmaceuticals, Inc.; Eli Lilly and Company; Intra-Cellular Therapies, Inc.; Pfizer, Inc; H. Lundbeck A/S; Sunovion Pharmaceuticals Inc:; Takeda Pharmaceutical Company Limited. Dr. Calabrese has served as a consultant/advisory board member/speaker for: Abbott Laboratories; Allergan; AstraZeneca; Bristol-Myers Squibb Company; Cephalon, Inc. (now Teva Pharmaceutical Industries Ltd.); Dainippon Sumitomo Pharma Co., Ltd.; GlaxoSmithKline; Janssen Pharmaceuticals, Inc.; H. Lundbeck A/S,Merck \& Co., Inc.; Otsuka Pharmaceutical Co., Ltd.; Pfizer, Inc; Repligen Corporation; Servier; Sunovion Pharmaceuticals Inc.; Solvay Pharmaceuticals, Inc.; Takeda Pharmaceutical Company Limited. Dr. Gao has been on a speaker's bureau of Sunovion and was on an advisory aboard of Sunovion. He received grant support from AstraZeneca, Brain and Behavior Research Foundation, and Cleveland Foundation. Dr. Ketter has the following financial interests/ arrangements or affiliations that could be perceived as real or apparent conflicts of interest: Grant/Research Support from the AstraZeneca Pharmaceuticals LP, Cephalon Inc., Eli Lilly and Company, Pfizer Inc., and Sunovion Pharmaceuticals; Consultant Fees from Allergan, Inc., Avanir Pharmaceuticals, Bristol-Myers Squibb Company, Cephalon Inc., Forest Pharmaceuticals, Janssen Pharmaceutica Products, LP, Merck \& Co., Inc., Sunovion Pharmaceuticals, Teva Pharmaceuticals; Lecture Honoraria from Abbott Laboratories, Inc., AstraZeneca Pharmaceuticals LP, GlaxoSmithKline, and Otsuka Pharmaceuticals; and Publication Royalties from American Psychiatric Publishing, Inc. In addition, Dr. Ketter's spouse is an employee of and holds stock in Janssen Pharmaceuticals. Dr. Shelton has been a consultant for: Allergan, Inc., Cerecor, Inc., Cyberonics, Inc., Janssen Pharmaceutica, Medtronic, Inc., Naurex, Inc., Nestle'Health Science, Pfizer, Inc., Takeda Pharmaceuticals. Grant/Research Support: Allergan, Inc., Assurex, Inc., Avanir Pharmaceuticals, Cerecor, Inc., Genomind, Janssen Pharmaceutica, Naurex, Inc., Novartis Pharmaceuticals, Otsuka America, Nestle' Health Science, Takeda Pharmaceuticals. Dr. McElroy is a consultant to or member of the scientific advisory boards of Allergen, Alkermes, Corcept, Ironshore, MedAvante, Naurex, NovoNordisk, Shire, Sunovian, and Teva. She is a principal or co-investigator on studies sponsored by the Agency for Healthcare Research \& Quality (AHRQ), Azevan, Alkermes, AstraZeneca, Cephalon, Eli Lilly and Company, Marriott Foundation, National Institute of Mental Health, Orexigen Therapeutics, Inc., Shire, Sunovian,Takeda Pharmaceutical Company Ltd., and Transcept Pharmaceutical, Inc. She is also an inventor on United States Patent No. 6,323,236 B2, Use of Sulfamate Derivatives for Treating Impulse Control Disorders, and along with the patent's assignee, The University of Cincinnati, Cincinnati, Ohio, has received payments from Johnson \& Johnson, which has exclusive rights under the patent. Dr. Friedman receives royalties from Springer. Mr. Rabideau reports no competing interests. Dr. Nierenberg is a consultant for Abbott Laboratories, Alkermes, American Psychiatric Association, Appliance Computing Inc. (Mindsite), Basliea, Brain Cells, Inc., Brandeis University, Bristol Myers Squibb, Clintara, Corcept, Dey Pharmaceuticals, Dainippon Sumitomo (now Sunovion), Eli Lilly and Company, EpiQ, L.P./ Mylan Inc., Forest, Genaissance, Genentech, GlaxoSmithKline, Healthcare Global Village, Hoffman LaRoche, Infomedic, Intra-Cellular Therapies, Lundbeck, Janssen Pharmaceutica, Jazz Pharmaceuticals, Medavante, Merck, Methylation Sciences, NeuroRx, Naurex, Novartis, PamLabs, Parexel, Pfizer, PGx Health, Otsuka, Ridge Diagnostics Shire, Schering-Plough, Somerset, Sunovion, Takeda Pharmaceuticals, Targacept, and Teva; consulted through the MGH Clinical Trials Network and Institute (CTNI) for Astra Zeneca, Brain Cells, Inc, Dianippon Sumitomo/Sepracor, Johnson and Johnson, Labopharm, Merck, Methylation Science, Novartis, PGx Health, Shire, Schering-Plough, Targacept and Takeda/Lundbeck Pharmaceuticals. He is a stakeholder in Appliance Computing, Inc. (MindSite), Brain Cells, Inc., and Medavante. He receives research support from American Foundation for Suicide Prevention, AHRQ, Brain and Behavior Research Foundation, Bristol-Myers Squibb, Cederroth, Cephalon, Cyberonics, Elan, Eli Lilly, Forest, GlaxoSmithKline, Intra-Cellular Therapies, Janssen Pharmaceutica, Lichtwer Pharma, Marriott Foundation,
Mylan, NIMH, PamLabs, PCORI, Pfizer Pharmaceuticals, Shire, Stanley Foundation, Takeda, and Wyeth-Ayerst. Honoraria include Belvoir Publishing, The University of Texas Southwestern Dallas, Brandeis University, Bristol-Myers Squibb, Hillside Hospital, American Drug Utilization Review, American Society for Clinical Psychopharmacology, Baystate Medical Center, Columbia University, CRICO, Dartmouth Medical School, Health New England, Harold Grinspoon Charitable Foundation, IMEDEX, International Society for Bipolar Disorder, Israel Society for Biological Psychiatry, Johns Hopkins University, MJ Consulting, New York State, Medscape, MBL Publishing, MGH Psychiatry Academy, National Association of Continuing Education, Physicians Postgraduate Press, SUNY Buffalo, The University of Wisconsin, The University of Pisa, The University of Michigan, The University of Miami, The University of Wisconsin at Madison, APSARD, ISBD, SciMed, Slack Publishing and Wolters Klower Publishing, ASCP, NCDEU, Rush Medical College, Yale University School of Medicine, NNDC, Nova Southeastern University, NAMI, Institute of Medicine, CME Institute, ISCTM, World Congress on Brain Behavior and Emotion, Congress of the Hellenic Society for Basic and Clinical Pharmacology, and ADAA. He has copyright joint ownership with MGH for Structured Clinical Interview for MADRS and Clinical Positive Affect Scale.

\section{Consent to publish}

Consent to publish this work has been obtained from the participant (or legal parent or guardian for children) to report individual patient data.

\section{Ethics, consent, and permissions}

This study was approved by the Internal Review Board at the Coordinating Center for this study, or Massachusetts General Hospital (Protocol \# 2010P001442), as well as the Internal Review Boards at each study site. All participants were consented to participate in this study.

Received: 29 July 2016 Accepted: 20 January 2017

Published online: 27 March 2017

\section{References}

Abraham K, Miller C, Birgenheir D, Lai Z, Kilbourne A. Self-efficacy and quality of life among people with bipolar disorder. J Nerv Ment Dis. 2014;202(8):583-8.

Adler N, Newman K. Socioeconomic disparities in health: pathways and policies. Health Aff. 2002;21 (2):60-76.

Bowden C, Singh V, Thompson P, Gonzalez J, Katz M, Dahl M, et al. Development of the bipolar inventory of symptoms scale. Acta Psychiatr Scand. 2007;116(3):189-94.

Bowie CR, Depp C, McGrath JA, Wolyniec P, Mausbach BT, Thornquist MH, Luke J, Patterson TL, Harvey PD, Pulver AE. Prediction of real-world functional disability in chronic mental disorders: a comparison of schizophrenia and bipolar disorder. Am J Psychiatry. 2010;167(9):1116-24.

Boylan KR, Bieling PJ, Marriott M, Begin H, Young LT, MacQueen GM. Impact of comorbid anxiety disorders on outcome in a cohort of patients with bipolar disorder. J Clin Psychiatry. 2004;65(8):1 106-13.

Brennan S, Williams L, Berk M, Pasco J. Socioeconomic status and quality of life in population-based Australian men: data from the Geelong Osteoporosis study. Aust NZ J Public Health. 2013;37(3):226-32.

Depp CA, Davis CE, Mittal D, Patterson TL, Jeste DV. Health-related quality of life and functioning of middle-aged and elderly adults with bipolar disorder. J Clin Psychiatry. 2006;67(2):215-21.

Duncan OD. A socioeconomic index for all occupations. 1996. Class: Crit Concepts. 1961;1.

Endicott J, Nee J, Harrison W, Blumenthal R. Quality of life enjoyment and satisfaction questionnaire. Psychopharmacol Bull. 1993;29(2):321-6.

Fulford D, Peckham A, Johnson K, Johnson S. Emotion perception and quality of life in bipolar I disorder. J Affect Disord. 2014;152:491-7.

Gazalle F, Hallal P, Andreazza A, Frey B, Kauer-Sant'Anna M, Weyne F, et al. Manic symptoms and quality of life in bipolar disorder. Psychiatry Res. 2007:153(1):33-8

Hirschfeld R, Calabrese JR, Weissman MM, Reed M, Davies MA, Frye MA, et al. Screening for bipolar disorder in the community. J Clin Psychiatry. 2003;64(1):53-9.

Huxley N, Baldessarini RJ. Disability and its treatment in bipolar disorder patients. Bipolar Disord. 2007;9(1-2):183-96. 
Judd LL, Akiskal HS. The prevalence and disability of bipolar spectrum disorders in the US population: re-analysis of the ECA database taking into account subthreshold cases. J Affect Disord. 2003;73(1):123-31.

Leon A, Solomon D, Mueller T, Endicott J, Posternak M, Judd L, et al. A brief assessment of psychosocial functioning of subjects with bipolar I disorder: the LIFE-RIFT. longitudinal interval follow-up evaluation-range impaired functioning tool. J Nerv Ment Dis. 2000;188(12):805-12.

Lorant V, Deliège D, Eaton W, Robert A, Philippot P, Ansseau M. Socioeconomic inequalities in depression: a meta-analysis. Am J Epidemiol. 2003;157(2):98-112.

McElroy SL, Altshuler LL, Suppes T, Keck PE Jr, Frye MA, Denicoff KD, et al. Axis I psychiatric comorbidity and its relationship to historical illness variables in 288 patients with bipolar disorder. Am J Psychiatry. 2001;158(3):420-6.

Mendlowicz MV, Stein MB. Quality of life in individuals with anxiety disorders. Am J Psychiatry. 2000;157(5):669-82.

Mielck A, Vogelmann M, Leidl R. Health-related quality of life and socioeconomic status: inequalities among adults with a chronic disease. Health Quality Life Outcomes. 2014;12(1):58.

Nierenberg AA, Sylvia LG, Leon AC, Reilly-Harrington NA, Shesler LW, McElroy $S L$, et al. Clinical and health outcomes initiative in comparative effectiveness for bipolar disorder (bipolar CHOICE): a pragmatic trial of complex treatment for a complex disorder. Clin Trials. 2014;11(1):114-27.

Oakes JM, Rossi PH. The measurement of SES in health research: current practice and steps toward a new approach. Soc Sci Med. 2003;56(4):769-84.

Otto M, Simon N, Wisniewski S, Miklowitz D, Kogan J, Reilly-Harrington N, et al. Prospective 12-month course of bipolar disorder in out-patients with and without comorbid anxiety disorders. Br J Psychiatry. 2006;189(1):20-5.

Rapaport MH, Clary C, Fayyad R, Endicott J. Quality-of-life impairment in depressive and anxiety disorders. Am J Psychiatry. 2005;162(6):1171-8.

Rosa AR, Reinares M, Michalak EE, Bonnin C, Sole B, Franco C, et al. Functional impairment and disability across mood states in bipolar disorder. Value Health. 2010;13(8):984-8.
Sanchez-Moreno J, Martinez-Aran A, Tabares-Seisdedos R, Torrent C, Vieta E, Ayuso-Mateos J. Functioning and disability in bipolar disorder: an extensive review. Psychother Psychosom. 2009;78(5):285-97.

Shabani A, Ahmadzad-Asl M, Zangeneh K, Teimurinejad S, Kokar S, Taban $M$, et al. Quality of life in patients with bipolar I disorder: is it related to disorder outcome? Acta Medica Iranica. 2013;51(6):386-93.

Sheehan D, Lecrubier Y, Sheehan KH, Janavs J, Weiller E, Keskiner A, et al. The validity of the mini international neuropsychiatric interview (MINI) according to the SCID-P and its reliability. Eur Psychiatry. 1997;12(5):232-41.

Sierra P, Livianos L, Rojo L. Quality of life for patients with bipolar disorder: relationship with clinical and demographic variables. Bipolar Disord. 2005;7(2):159-65

Simon NM, Otto MW, Wisniewski SR, Fossey M, Sagduyu K, Frank E, et al. Anxiety disorder comorbidity in bipolar disorder patients: data from the first 500 participants in the systematic treatment enhancement program for bipolar disorder (STEP-BD). Am J Psychiatry. 2004;161(12):2222-9.

Suppes T, Dennehy E, Hirschfeld R. The Texas implementation of medication algorithms: update to the algorithms for treatment of bipolar I disorder. J Clin Psychiatry. 2005;66(7):870-86.

Sylvia L, Friedman E, Kocsis J, Bernstein E, Nierenberg A. Association of exercise with quality of life and mood symptoms in a comparative effectiveness study of bipolar disorder. J Affect Disord. 2013;151(2):722-7.

Thompson PM, Gonzalez JM, Singh V, Schoolfield JD, Katz MM, Bowden CL. Principal domains of behavioral psychopathology identified by the bipolar inventory of signs and symptoms scale (BISS). Psychiatry Res. 2010;175(3):221-6

Tohen M, Bowden C, Nierenberg A, Geddes J. Clinical trial design challenges in mood disorders. London: Elsevier Inc; 2015.

Victor SE, Johnson SL, Gotlib IH. Quality of life and impulsivity in bipolar disorder. Bipolar Disord. 2011;13(3):303-9.

\section{Submit your manuscript to a SpringerOpen ${ }^{\odot}$ journal and benefit from:}

- Convenient online submission

- Rigorous peer review

- Immediate publication on acceptance

- Open access: articles freely available online

- High visibility within the field

- Retaining the copyright to your article

Submit your next manuscript at springeropen.com 